\title{
El relato por otros medios: ¿un giro transmediático'?
}

\author{
Raúl RoDRÍGUEZ FERRÁNDIZ* \\ r.rodriguez@ua.es
}

(Abstracts y palabras clave al final del artículo)

Enviado: 20 de abril de 2013

Evaluado: 25 de junio de 2013

Aceptado: 1 de agosto de 2013

\section{INTRODUCCIÓN}

Las narraciones transmediáticas, o narraciones transmedia -en adelante NT- se han convertido en un tema de estudio desde hace al menos una década, a partir de los textos pioneros de Henry Jenkins a principios del nuevo siglo (Jenkins, 2003). El propio Jenkins fue matizando y enriqueciendo su tesis inicial (Jenkins, 2006, 2007, 2009a, 2009b, 2011a, 2011b), gracias a su capacidad para integrar aportaciones diversas (Johnson, 2009; Mittell, 2009; Dena, 2004, Long, 2007; Murray, 1997; Hills, 2002) tanto como a su condición de atento y ávido consumidor de creaciones transmedia y a la vez de profesor universitario que imparte cursos sobre NT, reflexiona sobre su metodología docente y la comparte (Jenkins, 2010). No por casualidad su blog se llama "Confessions of an Aca-Fan", que da fe de su -no tan común como se cree- condición de académico y de entusiasta fruidor de narraciones, sin que el rigor en el estudio de uno menoscabe el disfrute del otro. El término ha ido imponiéndose en medios académicos, en competencia con otros del mismo campo semántico aunque con matices distintos: cross-media, intertextualidad comercial, multiplataforma, hiperserialidad, hiperdiégesis, media hibridos, (Dena, 2004; Davidson, 2010; Hardy, 2011; Murray, 1999; Hills, 2001; sobre estos términos, cfr. Scolari, 2009 y 2013). Y finalmente ha sido también asumido en medios profesionales, deparando guías y manuales de uso para el creador transmedial (Giovagnoli, 2011, Bernardo, 2011, Phillips, 2012), e incluso recibiendo la sanción de la industria en 2010, cuando la Producers Guild of America añadió la categoría "transmedia producer" a la lista de créditos de los filmes de Hollywood.

1 Este trabajo ha sido escrito en el marco del proyecto de investigación $\mathrm{I}+\mathrm{D}+\mathrm{i}$ financiado por el Ministerio de Economía y Competitividad (Ref. FEM2012-33411), dirigido por la Prof. Rosario Lacalle (UAB), y en el que participa el autor. Se intenta con él enmarcar la ficción televisiva serial del nuevo milenio en el nuevo modelo creativo, tecnológico y económico que dibujan las narraciones transmediáticas.

* Profesor Titular del Departamento de Comunicación y Psicología Social de la Universidad de Alicante. Coordinador del Máster Oficial en Comunicación e Industrias Creativas. 


\section{NARRACIONES TRANSMEDIÁTICAS Y COMPLEJIDAD NARRATIVA}

Para Jenkins, las NT representan un fenómeno cultural característico de la "era de la convergencia", según el cual elementos sustanciales de una ficción narrativa son diseminados sistemáticamente a lo largo de canales diversos, con el fin de propiciar una experiencia de entretenimiento unificada y coordinada a través de todos ellos. Idealmente, cada medio hace una contribución exclusiva, distintiva y valiosa a la construcción de la historia, es decir, no se trata de una mera adaptación, transposición o traducción intersemiótica (Jenkins, 2007, 2009a, 2009b; Scolari, 2009: 589). Cada medio vehicula un texto que ofrece algo nuevo, de manera que el conjunto de la narración al tiempo se enriquece y se problematiza por ese aporte, y la "vecindad" intertextual que ayuda a construir se hace más densa y más compleja.

Se han propuesto algunas listas de rasgos para caracterizar una NT (Gomez, 2007; Jenkins, 2009a, Transmedia Manifest, 2011), que ponen el énfasis en aspectos no completamente coincidentes. En cualquier caso, es posible señalar unos principios básicos: 1) los múltiples medios y plataformas en que se disemina el universo narrativo; 2) la necesidad de que cada uno de ellos haga con dicho universo lo que sabe hacer mejor sin caer en redundancias, sino expandiéndolo y profundizándolo al mismo tiempo; 3) el balance calculado entre relatos que se sostengan por sí mismos en un sólo medio es decir, que no resulten incomprensibles para un público ocasional-, y relatos que sean fragmentos de un todo más comprensivo capaz de arrastrar a un público transmedial, más implicado, 4) la necesidad por ello de un control creativo centralizado, a veces incluso unipersonal, pero al tiempo 5) la inevitable dispersión del universo a partir de relatos no canónicos, producto de la creatividad irrestricta del usuario.

A nuestro juicio, lo más exigente desde el punto de vista narrativo es la "additive comprehension", término que Jenkins toma en préstamo del diseñador de videojuegos Neil Young: lo nuevo de la narración que llega a nuestras manos no es redundante, sino que debe, idealmente también, obligarnos a repensar significativamente nuestras asunciones previas sobre la historia. El ejemplo que pone Young y que Jenkins comenta en su libro es clarificador: en la segunda versión de Blade Runner (Ridley Scott, 1982), la que se comercializó en 1992 con el reclamo de "Director's Cut", hay una escena que no aparecía en la primera, un sueño de Deckard que muestra a un unicornio galopando por un bosque. Dicha escena, que en realidad procede del rodaje de Legend (1985), otro filme de Scott, cobra sentido cuando se relaciona con otra, hacia el final de la película, cuando Deckard descubre el unicornio de papel de aluminio en el vestíbulo de su vivienda, justo en el momento de huir de ella junto a Rachael. Ese detalle del "origami unicorn" - una afición del policía Gaff, encargado de supervisar la labor de los bladerunners- podría querer decir que ha estado allí y ha permitido sin embargo que Rachael escapara con vida. Pero juntas, nos hacen reconsiderar nuestras inferencias previas sobre Deckard y sospechar razonablemente que es también un replicante: el policía no podría conocer el sueño recurrente de Deckard, salvo si los recuerdos y sueños del bladerunner hubieran sido implantados artificialmente.

Pues bien, es obvio que las sucesivas versiones de Blade Runner (hay otra de 2007, apellidada "The Final Cut", remasterizada y con otros cambios menores) serí- 
an esbozos todavía de NT, y apenas alcanzan la categoría de transmedia -no salimos de la producción cinematográfica, aunque el todavía recién estrenado por entonces soporte DVD recogerá materiales que no son vistos en sala, y aunque la película suponga ya más de una vuelta de tuerca sobre la novela de Philip K. Dick. Ahora bien, esa es, a juicio de Jenkins, la manera de proceder de una producción transmedia del nuevo milenio: la adición de elementos que reactivan de alguna manera la tensión narrativa, que hurgan en cabos de la historia que habían quedado desatados, que abren a su vez nuevas incógnitas, haciendo de ella una potencial Neverending Story, como en aquella novela de Michael Ende llevada también al cine.

Las NT son en cierto modo la forma en que la historia reclama sus derechos sobre el relato, que la ha mutilado, recompuesto, montado de una manera efectista y con pretensión de clausurarla. Pero la historia se diría un universo vivo, que crece a espaldas de la atención selectiva que el relato presta a ciertos motivos, personajes o acciones, a espaldas incluso de la voluntad de autor y de quien lo produce y distribuye. Ahora bien, inapelablemente, esa historia vuelta a contar, en la que los detalles elididos, los personajes secundarios, los motivos ocultos adquieren protagonismo, cristaliza de nuevo en relato. Relatos que parten de los productores "corporativos", pero también de usuarios empoderados en cierto modo por las tecnologías digitales de la creación, el acceso y la circulación. Y esos relatos proliferan, en los casos ideales sin contradecirse, sino como apertura o diseminación de narraciones coordinadas que se expanden por un ecosistema mediático compuesto de diversos medios y plataformas, y que pueblan todas ellas el universo ficcional de la historia, amplio pero de personajes, escenarios, acciones, tramas de algún modo interdependientes.

Dicho esto, la paradoja estructural, digamos, de las NT, y con la que ha tenido que batallar Jenkins con resultados ambivalentes, es la siguiente: operan sumando textos cuyas sustancias y formas son muy diversas, de manera que la narración resulta no sólo tan extensa, sino también tan multimedial, intermedial (López-Varela, 2011) o multimodal (Kress y Van Leeuwen, 2001, Page, 2009), que no puede contenerse en un solo medio. Pero al tiempo, cada uno de esos textos en que se entrega parcialmente debe permitir disfrutes completos y autónomos. Ello, de evidente complejidad narrativa, responde sin duda, también, a un propósito comercial. La transmedialidad de los relatos dibuja no sólo varias puertas de entrada a la narración en cuanto a los medios frecuentados por los públicos (el aficionado a las series, o a los videojuegos, o a los cómics, a menudo no coincidentes y no interesados en los otros medios), sino que también establece pasarelas entre esos públicos distintos, a poco que su implicación y compromiso supere un cierto umbral. Es decir, al tiempo requiere y prevé, busca y modula a un destinatario inquieto, itinerante, que seguirá la narración allá donde esta quiera llevarle (Scolari, 2009: 597).

\section{ALGUNOS EJEMPLOS}

Según Jenkins, las primeras reflexiones en torno a las NT se produjeron tras el estreno y el éxito de dos filmes, The Matrix y The Blair Witch Project, ambos de 1999. En el caso de The Matrix la narración se diseminó en tres filmes (The Matrix 
(1999), The Matrix Reloaded (2003) y The Matrix: Revolutions (2003)), nueve cortos de animación recopilados en The Animatrix (2003), dos colecciones de cómics (webcomics entre 1999 y 2003, accesibles desde la página web oficial de la franquicia, y luego editados en papel en dos volúmenes en 2003 y 2004 como The Matrix Comics) y varios videojuegos (Enter the Matrix en 2003, The Matrix Online en 2004 y The Path of Neo en 2005). No se trataba de meras adaptaciones, ni de una franquicia a la antigua usanza, sino de extensiones. Matrix estaba dispersa por todos esos medios y plataformas, pero sujeta a un hilo narrativo que los coordinaba sistemáticamente y a un control creativo centralizado.

Y así, el corto The Second Renaissance (Mahiro Maeda, 2003) incluido en The Animatrix, era una precuela del primer filme de la trilogía, y relataba la construcción por los humanos de máquinas cada vez más sofisticadas y autónomas, el desprecio de los humanos por los robots, el primer asesinato cometido por un máquina y el juicio subsiguiente, la guerra entre humanos y máquinas, el sometimiento de los humanos a las máquinas y la construcción de Matrix. Dicho corto, a su vez, se inspiraba en un webcomic cuyo guion correspondía a los Wachowski, titulado "Bits and Pieces of Information", y que data de 1999, año del estreno del primer filme. Otro corto, Kid's Story (Shinichiro Watanabe, 2003, pero con guion de los Wachowski), era una historia intercalada que se ubicaba en el periodo de seis meses que en el tiempo narrativo ficcional separaba la primera de la segunda película, y presentaba a un niño con el que contacta Neo para tratar de sacarlo de Matrix. La película The Matrix Reloaded hace alusión a este episodio que está en el corto Kid's Story, pero no en la primera entrega. Finalmente, el corto Final Flight of the Osiris dentro de la colección The Animatrix, con guion de nuevo de los Wachowski, apelaba a un momento narrativo inmediatamente anterior a los hechos narrados en el segundo filme: los últimos minutos de la tripulación de la nave Osiris, que es la que descubre el ejército de centinelas que las máquinas tienen preparado en la superficie de la Tierra. Detectado por los centinelas, la nave huye y se inicia una persecución, en el curso de la cual una tripulante, Jue, se introduce en Matrix y deja un mensaje a través del correo postal, dirigido a los tripulantes de la nave Nabuconodosor. La entrega de dicho mensaje será la primera misión de los jugadores del videojuego Enter the Matrix, encarnados en los personajes Niobe y Ghost -secundarios en la trama, al menos en los dos primeros filmes. Y en The Matrix Reloaded Niobe hace alusión a "las últimas transmisiones de la Osiris", algo que no se mencionaba en el primer filme, y que precisa ahora de la apelación a dos medios "intermedios" o "transmedios" para alcanzar pleno sentido. The Animatrix contiene asimismo cortos que no pueden ser ubicados temporalmente en algún punto de la saga de films: son historias periféricas, distantes de la trama principal, pero amueblan el universo ficcional y lo hacen más consistente. A Detective Story (Shinichiro Watanabe, 2003) por ejemplo, que tiene el aire de un filme noir, presenta a un detective que recibe de forma anónima el encargo de encontrar a una delincuente conocida como Trinity.

Finalmente, el videojuego The Matrix Online era una secuela de la trilogía de filmes que, sorpresivamente, decidió acabar con el personaje de Morfeo en mayo de 2005, prolongando sin embargo la narración con misiones motivadas por esa muerte. Otro videojuego, Path of Neo, pone al jugador en la piel de Neo, el protagonista, 
y en la situación de algunas de las escenas más conocidas del primer film. Podría considerarse una adaptación de estas escenas a la "jugabilidad" que exigen los videojuegos, que incluye tanto metraje extraído del primer film como clips procedentes de The Animatrix y de Enter the Matrix. Ahora bien, en cierto modo lo que nos propone el videojuego es la posibilidad de modificar acontecimientos que ocurren de cierta forma en la película y que por obra de la actividad del jugador (un NeoNeo, digamos) pueden ocurrir de forma distinta.

En definitiva, el macrodiseño narrativo invitaba al espectador cinematográfico a buscar claves ajenas a los textos fílmicos, abriendo su apetito por otros medios y otros textos, pero también jugaba con la repetición, adaptada a otro medio, plataforma, uso y usuario, de motivos ya conocidos desde dicha trilogía de filmes.

En el caso de The Blair Witch Project, los productores y directores del film (Daniel Myrick y Eduardo Sánchez) difundieron, un año antes del estreno de la película, un sitio web que contaba la historia de la bruja y de la desaparición del equipo de rodaje, supuestamente ocurrido en 1994. En él aportaron falsas evidencias fotográficas, falsos cortes de informativos y de reportajes sobre la investigación policial, supuestas entrevistas a familiares, amigos y profesores de los chicos, testimonios de historiadores y antropólogos de la zona, que despertaron mucho interés entre los internautas.

Pocas semanas antes del estreno del filme, en julio de 1999, Sci Fi Channel emitió un documental titulado Curse of the Blair Witch, dirigido por los propios Myrick y Sánchez, donde se recogían todos estos materiales con un fuerte toque realista. Y ese documental televisivo, a su vez, se materializó en una publicación en papel (The Blair Witch Project: A Dossier, de 1999). Tras el estreno de la película se editaron comics supuestamente basados en los testimonios de otra persona que se encontró a la bruja (The Blair Witch Project Comics), se lanzó un CD musical con los temas de rock gótico supuestamente contenidos en el cassette de uno de los chicos encontrado en el coche (Josh Blair Project Mix), se fabricaron y comercializaron objetos que formaban parte del attrezzo del filme o de su universo narrativo (como el diario de Heather Donahue, la chica desaparecida), se editó una colección de ocho libros para adolescentes protagonizados por un familiar de la joven desaparecida, que investiga las circunstancias de la desaparición (The Blair Witch Files). También hubo contribuciones en otro tono: Sergio Aragonés, un afamado dibujante de comics de origen español, lanzó el cómic Blair Which?, una parodia de la película en la que eran un grupo de boy-scouts los causantes del terror en los miembros del equipo de filmación. Lo cual abundaba, a su manera, en la ficción, no la ponía en duda metaficcionalmente. Finalmente hubo una secuela cinematográfica en 2000, con guion también de Myrick y Sánchez (Book of Shadows: Blair Witch 2) y tres videojuegos, también en 2000, que volvían sobre el escenario de Burkittsville y los sucesos paranormales, pero en tres momentos cada vez más distantes en el tiempo de los hechos narrados en la película: los años 40, la época de la Guerra Civil americana, y un episodio de caza de brujas datado en 1785, y que pretende ser el origen de la historia.

Como se aprecia en los ejemplos, hablamos siempre de narraciones, que 1) admiten y potencian esa voluntad transmedial y ese furor por el detalle, incluso el que abunda en los márgenes, en la periferia del relato, y ello porque a menudo dise- 
ñan un universo extraordinariamente intrigante, y estimulan el deseo de recorrerlo en toda su extensión, con una especie de voracidad enciclopédica; 2) buscan la participación, la implicación de los fans, que se integran en comunidades colaborativas muy activas, pues de la misma manera que el relato no puede contenerse en un solo medio, tampoco existe el receptor capaz de contener en su cabeza los detalles completos de una narración dispersa y proliferante y 3) tanto la dispersión transmedial por un lado como la implicación de los receptores, por otro, no son parasitarias, sino simbióticas, con respecto a la narración principal: hay una retroalimentación entre las estrategias productoras, corporativas y las tácticas del consumo amateur pero participante, de las fuerzas top-down y de las fuerzas bottom-up.

\section{TRANSMEDIACIONES DE LAS FICCIONES TELEVISIVAS}

Hemos hablado hasta ahora de ejemplos que tienen como "naves nodriza" de la NT a filmes. Para quien sostuviera todavía una reserva mental con respecto a las posibilidades narrativas de la televisión, quizá haya resultado sorprendente que las NT hayan anidado allí con inusitado vigor, convirtiéndose a día de hoy en el centro de infinidad de galaxias del universo narrativo transmedial. No hace tanto tiempo la televisión era considerada, por condiciones inherentes a la pequeña pantalla, al visionado doméstico, a la emisión ininterrumpida en tanto flujo pero con interrupciones publicitarias, a la competencia entre cadenas y al comportamiento inconstante de la audiencia dotada de mando a distancia, como un medio incapaz de procurar genuinas experiencias narrativas intensas. Y ello desde Adorno a Popper, desde Postman a Bourdieu, desde Virilio a Sartori (Rodríguez Ferrándiz, 2001). La televisión, y en particular sus formatos ficcionales genuinos, caracterizados por la serialización, eran el lugar de narraciones consolatorias y redundantes, no nutritivas y exigentes. Y sin embargo, parece obvio que de un tiempo a esta parte una hornada de series televisivas han mostrado una atracción inusitada por la complejidad (Mittell, 2006), y a ese desafío ha acudido un público quizá no masivo, pero sí implicado. Y ello para una gran variedad de géneros: el policíaco o forense (The X-Files, 24, CSI, Dexter, Fringe), el terror (Buffy Cazavampiros, True Blood), la ciencia ficción (Doctor Who, Battlestar Galactica), el misterio (Lost), etc ${ }^{2}$. Y es precisamente la circunstancia de la serialidad la que garantiza una implicación a largo plazo del espectador, pues la emisión abarca años y cientos de horas de programación, y esa prolongación de la intriga es inasequible o difícil de mantener para otros medios de expresión narrativa (Askwith, 2007; Smith, 2009; Evans, 2008, 2011).

La serie norteamericana True Blood (2008-) puede resultar un ejemplo paradigmático de la transmedialidad narrativa en la ficción televisiva (Rodríguez Ferrándiz, 2012). Se trata de una serie - un serial, para ser más precisos- de la cadena de cable

2 Sobre Lost, Askwith, 2007: 117-149; Smith, 2009: 70-105; Pearson 2009; Maguregui, Piscitelli, Scolari, 2010. Sobre Doctor Who, Perryman, 2008; sobre 24, Scolari, 2009; sobre True Blood, Hardy, 2011 y Rodríguez Ferrándiz, 2012. 
norteamericana $\mathrm{HBO}$, estrenada en septiembre de 2008 y ya con una sexta temporada concluida y una séptima anunciada, que será la última.

True Blood sitúa la acción en Bon Temps, un pequeño pueblo ficticio ubicado en Luisiana, y en una época que podría ser la nuestra. Pero arranca, ya desde el episodio piloto, con un modelo de mundo fantástico: se da por descontado que los vampiros existen. El acontecimiento desencadenante consiste en que científicos japoneses han desarrollado una bebida sintética -Tru Blood- que cubre sus necesidades nutricionales. Ya no vampirizan por necesidad, clandestina y criminalmente, sino que salen del ataúd y buscan reconocimiento civil y político. La cuestión es que el sucedáneo no convence a todos, de manera que hay vampiros integracionistas y vampiros contumaces, y por lo tanto su pleno reconocimiento está sembrado de dificultades. Al terror inmemorial se une la desconfianza y la victimización. Así las cosas, se ha constituido la American Vampire League, que aboga por la aprobación en el Congreso de la "Vampire Rights Amendment". Y del otro lado está The Fellowship of the Sun, una asociación integrista cristiana que aboga por el aislamiento de los vampiros y que evoluciona hacia una organización paramilitar que perpetra atentados contra ellos.

La trama se complica extraordinariamente cuando nos percatamos de que al tiempo que la sangre humana puede no ser ya vital para los vampiros ("Real Blood is only for suckers", reza el slogan de la bebida), la sangre de vampiro -el zumo Vse convierte en una droga altamente adictiva para los seres humanos. Algunos humanos vampirizan a vampiros hasta matarlos, consumiendo su sangre o traficando con ella, y algunos vampiros trafican incluso con su propia sangre, conscientes de su valor, pero contraviniendo leyes sagradas para ellos.

Se diría que su origen como tal serie -y centro de un universo narrativo transmediático- no era demasiado genuino ni resultaba quizá prometedor: no se trata de un guion original, sino adaptado a partir de la saga de novelas de Charlaine Harris, The Southern Vampires Mysteries, que se inició en 2001 y ha lanzado ya su decimotercera entrega en mayo de 2013, a razón de libro por año. Es decir, a diferencia de otras series nacidas transmediáticas como 24, Lost o The Wire, True Blood tenía un urtext, era en principio la adaptación de un texto literario previo. Ahora bien, la serie se convirtió en buque nodriza de un universo transmedial que en cierto momento absorbió en su seno a la propia saga literaria.

Los libros de Harris, que a partir del octavo (2008) se simultanearon con las sucesivas temporadas de la serie, pero con un desfase de 8 libros -siendo cada temporada la adaptación de un libro, más o menos- entraron en sintonía retrospectiva con la serie. Para los trubbies los libros funcionaron de hecho como secuelas literarias de la serie televisiva y promesas - que se verán, o no, cumplidas- de una futura versión televisiva. Por otro lado, Harris desarrolló, a partir de 2004, una expansión literaria -aunque en el género del cuento de terror vampírico- de su universo novelístico, de manera que desde entonces han aparecido hasta catorce relatos, recogidos en diferentes antologías del género. Los cuentos forman cuerpo con el universo de True Blood, a la manera en que lo hemos visto en la saga de Matrix: se trata bien de "relatos intersticiales" - que cubren tiempos narrativos muertos en el relato de la saga de novelas- o bien de "relatos simultáneos" -que cuentan historias que suce- 
den contemporáneamente a otras de la saga pero protagonizadas en los cuentos por personajes que era secundarios en las novelas. El orden de publicación de los cuentos no sigue la cronología de la historia que es narrada en los libros: algunos cuentos deberían leerse antes que algunos libros publicados con anterioridad. Algunos libros tienen como protagonista a Sookie Stackhouse, la protagonista de la saga, en otros no comparece ella aunque sí su universo narrativo.

Más allá de la labor literaria de Harris, en plena sintonía con Alan Ball, el showrunner de la serie, y con los directivos de la HBO, la expansión transmediática del universo truebloodiano ha sido intensiva y extensiva: cómics, guías o ensayos sobre el universo narrativo, revistas, banda sonora original de la serie editada en $\mathrm{CD}$, recopilatorios por temporada de los temas musicales de cierre de cada episodio, que incluyen temas clásicos (Depeche Mode, Lady Gaga), covers o versiones más recientes (Talking Heads, The Zombies) y temas expresamente compuestos para la serie (Iggy Pop), páginas web oficiales que permiten acceder a contenidos narrativos exclusivos, como webisodes o minisodes, aplicaciones para teléfono móvil, juegos on line y off line sobre la serie y merchandising muy variado.

Toda esa expansión mercantil de la serie entra en relaciones variadas con la trama narrativa de la misma, procurando transmediaciones de distinto grado: desde productos que dibujan claramente una galaxia transmedial -como los cuentos de Harris, los webisodios y minisodios, algunas colecciones de cómics- hasta otros más alejados, aunque nunca inertes narrativamente hablando, como algún tipo de merchandising "diegético" (Johnson, 2007:15-16). En una tercera categoría, a nuestro juicio extremadamente interesante, entrarían aquellos productos que precisan de la complicidad del receptor para engastar el producto y su uso o su disfrute en el universo narrativo, como las canciones cuyas letras pulsan armónicos de las notas fundamentales de la trama o son interpretados por cantantes o grupos "resonantes" con el modelo de mundo de la serie, o como las marcas comerciales que hicieron campañas asociándose al mundo truebloodiano y asumieron un storytelling y un "diseño de producción" congruente con ese mundo (Harley Davidson, Gillette, Mini, Marck Ecko, Sephora). Porque -es un aspecto que hemos abordado en otro lugartoda esa producción fastuosa y coordinada tuvo una réplica en la actividad de los fans, extraordinariamente prolífica y competente: canales de Youtube, páginas web, actividad en las redes sociales, tráilers y cabeceras, todas ellas no oficiales, recapitulaciones y selecciones de escenas confeccionadas por los usuarios, fanfiction y twitterfiction en forma de relatos intersticiales, pero fuera del canon de la serie; videos amateurs con parodias, que llegaron en algunos casos a cristalizar en webseries, juegos...(Rodríguez Ferrándiz, 2012: 75-76).

En cualquier caso, el rasgo a nuestro juicio más distintivo de la estrategia transmedial de True Blood fue la campaña de lanzamiento de la serie, orquestada en tres fases sucesivas: introducción, integración (de los vampiros en sociedad) y focalización (en el escenario principal de Bon Temps). La introducción consistió en una serie de acciones cuidadosamente planificadas: cartas anónimas remitidas a blogueros influyentes, con indicaciones crípticas sobre la inminente visibilidad de los vampiros, que remitían a una web a partir de la resolución de algunos enigmas vía ARG (Alternate Reality Game, Dena, 2008); la propia página web, donde vampiros japo- 
neses daban cuenta de la invención de la bebida (slogan: "All Flavour, No Bite") y establecían un foro donde participaban vampiros del mundo que la habían probado; una segunda carta a los blogueros, con tubos de ensayo que contenían muestras del producto; otra web donde se trazaba la actividad de los vampiros en la red, y finalmente un cómic (True Blood: The Great Revelation), lanzado poco antes del estreno de la serie, que mostraba su modelo de mundo sin ofrecer detalles sobre los protagonistas, sino focalizado en otros secundarios o anecdóticos.

La integración o segunda fase consistió en la articulación de una controversia en la red a través de dos páginas web, la integracionista American Vampire League y la segregacionista The Fellowship of the Sun. Ambas con todo el argumentario y el aparato propagandístico propios de cualquier organización social con objetivos políticos: logos, lemas, compromisos, carteles, vídeos con declaraciones de los líderes, tomas de posición de personajes públicos, de la política o de otros ámbitos, entrevistas a gente de la calle. Y todo ello en plena campaña electoral presidencial en EE.UU, la que llevó a la presidencia a Obama. Las páginas simulaban un activismo tan entusiasta, una virulencia tan enconada, que no hizo sino instar ese mismo apasionamiento entre una comunidad naciente de fans. La página de la AVL incluía además vídeos de vampiros de todo el mundo reclamando sus derechos, así como un noticiario vampírico, incluso con publicidad de productos y servicios adaptados a las necesidades o a las capacidades de los vampiros: abogados, hoteles, dentistas, páginas de contactos.

La focalización o tercera fase consistió en la presentación del escenario y de los personajes de la serie, ya localizada en Bon Temps y en los prolegómenos de la historia que será contada en ella. Se trataba de vídeos breves: posible ataque de un vampiro en Bon Temps, entrevista al sheriff del condado, a los que serían luego protagonistas de la serie. Incluía también el mockumentary o falso documental In Focus: Shedding Light on Vampires in America (con títulos de crédito al final, declarando que lo era). En él se entrevistaba a los científicos japoneses autores del invento, se daba a conocer a algunos de los personajes y lugares que aparecerán en la serie -el bar Merlotte's en Bon Temps, por ejemplo- y se daba voz tanto a los activistas de la AVL como a los de la Comunidad del Sol.

Pues bien, toda esa producción narrativamente relevante pero librada de forma gratuita con finalidad promocional debe sin duda considerarse parte del universo transmedial trubloodiano. La campaña de lanzamiento fue un verdadero prólogo de la serie en sí, ausente en el urtext novelístico de Harris. Y las acciones promocionales orquestadas en los recesos entre las temporadas pueden considerarse como subtramas que mantienen el interés sobre el mundo de la serie, que lo catalizan (Barthes, 1993:175), que contribuyen a amueblarlo (Eco, 1992: 216-219) en pie de igualdad con otros productos culturales digamos "genuinos" y en apariencia "finales".

Si atendemos al modelo ideal de NT diseñado por Jenkins (2007) y expuesto arriba, entonces todos esos productos promocionales -paratextuales diría Genette (1987), sean peritextuales o epitextuales- deben jugar el mismo papel que los propios textos: su función es apuntalar el universo ficcional con contribuciones exclusivas y multiplicar la densidad del espacio y del tiempo narrativos para crear una experiencia más intensa y más cautivadora, sin por ello agotar su potencial. Un por- 
ción importante -y creciente, a nuestro juicio- de esos productos promocionales están diseñados no solo y no principalmente con el fin de extractar con imágenes impactantes y prescribir el producto en sí -la función tradicional del teaser, del tráiler, de la promo-, sino con el de reforzar el mundo ficcional y contribuir a proporcionar una inmersión más envolvente.

De esta forma llegamos a una situación paradójica y liminar: es cierto que los productos culturales que generan valor económico, pues vendidos como paquetes creativos y sometidos a derechos de autor (libros, cómics, filmes, series de televisión, videojuegos, etc.), se promocionan entre sí de forma cruzada en tanto componentes de un universo narrativo transmediático, pues cada uno de ellos hace mención explícita o implícita a los demás, con la web como metamedio que los contiene, enlazados, a todos ${ }^{3}$. Pero también es cierto que los productos promocionales que se ofrecen gratis a las audiencias (mobisodes, webisodes, sitios web, blogs) adquieren una dimensión narrativa: el relato empieza, prosigue, se refuerza, se adensa, también, a través del contenido promocional.

\section{OBJECIONES A LAS NT}

Para finalizar, expondremos por un lado las críticas que ha recibido el concepto, distinguiendo entre las objeciones generales, de calado, y las apostillas que precisan algún aspecto concreto, y por otro los retos que plantean. Un debate que puede suponer una enmienda a la totalidad es el que atañe a las dudas sobre la novedad del fenómeno: si las NT estaban ya en los relatos bíblicos, la épica homérica o el BhágavadGuitá -como sostiene Bordwell, 2010-, o bien encuentra ejemplos muy consistentes en los universos de Tolkien, C.S. Lewis, Disney, DC, Marvel, o George Lucas, muy anteriores a la era digital, entonces la reflexión sobre ellas en la actualidad debe moderar su alcance, en tanto modulación de un fenómeno que viene de antiguo y que la era de la convergencia solo habría exacerbado o enfatizado, proyectando desde luego una nueva luz sobre las arquitecturas narrativas en el pasado. Si el fenómeno llamado NT viene de antiguo, se diría que la reflexión sobre el mismo también: en cierto modo, la teoría que vendría a ofrecer las reglas del juego sobre las que despliegan sus estrategias y sus tácticas las NT es la de la intertextualidad, que se remonta a las especulaciones de Kristeva y Barthes en los años sesenta, y que alcanzó un alto grado de formalización con la transtextualidad de Genette (1989). En sus conocidas taxonomías ya se contemplaba tanto una hipertextualidad como una paratextualidad, a las que Genette dedicó sendas monografías (1989 [1982], 1987), y que recubren en buena medida la casuística de las "narraciones transmediales" descritas

\footnotetext{
${ }^{3}$ Las reediciones de las novelas de Harris incorporan el logo de la serie y la cadena en la portadas, como también lo hacen las portadas de los CD de la banda sonora y de los recopilatorios por temporada de los temas principales de cada episodio. Los DVD de la serie incluyen como extras algunos de los materiales usados en la campaña de lanzamiento (mobisodios, websisodios, videos de confesiones de vampiros, campañas cívicas en pro y en contra de su integración, anuncios falsos dirigidos a ese target ficcional...). Los sitios web de la HBO ponen todo el material, sea de pago o promocional, al alcance del visitante.
} 
por Jenkins. En particular, se habla de conceptos tales como extensión (1989: 329 y ss.), expansión (335 y ss.), transmodalización (356 y ss.) y transfocalización, que darían cuenta de algunas de las transformaciones tanto formales como temáticas que sufre el relato en su centrifugación transmediática. Ahora bien: si los fenómenos pueden haber sido descritos e ilustrados, sin duda lo fueron a otro propósito: una red intertextual es la condición necesaria, pero no suficiente para hablar de NT.

Jenkins concedió en Convergence Culture que a su fórmula es posible encontrarle precedentes, pero arguyó que el término NT sin duda ha adquirido una dimensión nueva en su uso contemporáneo, un sentido que tiene que ver con la creación de un mundo ficcional amplio y coherente, planificado desde un núcleo creativo centralizado, que es librado a la audiencia en múltiples formatos, para lo cual la emergencia de las tecnologías digitales y telemáticas han jugado un papel clave, no sólo desde la producción, sino también desde una recepción implicada y colaborativa. Es esa participación no solo crítica, sino creativa, coproductiva, de un usuario empoderado por la web 2.0 la que otorga a las NT su peculiar vigor. Es ella la que trasfigura la devoción y el coleccionismo propios de cualquier fenómeno fan en compromiso e implicación, en activación de competencias propiamente narrativas. La que mueve desde el comentario crítico, el elogio o la reprobación, es decir, desde habilidades metatextuales (por seguir con la tipología genettiana), a la creación de continuaciones o antecedentes, de homenajes o parodias, de historias paralelas o amplificaciones de una trama quizá circunscrita a un canon, pero que se escapa inevitablemente hacia los territorios no mapeados de antemano del fandom: destrezas hipertextuales y paratextuales que retroalimentan en algunos casos la propia producción oficial, corporativa (Lacalle, 2011).

En cualquier caso, no podemos entrar aquí en una reconstrucción histórica del avatar de la narración transmedia o de sus equivalentes, con otra terminología, a lo largo del tiempo ${ }^{4}$. Solo advertiremos que los precedentes que se han señalado, o que podrán señalarse, deberían cumplir con los requisitos expuestos arriba. No nos cansaremos de repetir que la narración transmedia debe conjugar, y no solo yuxtaponer, ambas partes del sintagma y atender suficientemente al prefijo trans-: no se trata de narraciones enteras y verdaderas que son vertidas a otros medios practicando modificaciones más o menos profundas (eso son adaptaciones o traducciones intersemióticas, conocidas desde los albores de la expresión artística en forma narrativa), y tampoco son mensajes que, con independencia de su naturaleza (acaso no narrativa, o narrativa solo traslaticia o figuradamente), se reparten a lo largo de medios distintos.

Por otro lado, hay varios debates que tienen que ver con enmiendas parciales. Jason Mittell sugiere que las NT no hablan tanto de extensión o diseminación (como proponía Jenkins, en una imagen horizontal) como de profundización (del fan hardcore exigente): para Mittell lo característico de las NT no es tanto la extensión horizontal del fenómeno (un fenómeno de masas atraídas por medios distintos pero complementarios), sino la capacidad de movilizar a comunidades relativamente peque-

\footnotetext{
${ }^{4}$ Sobre la prolífica promiscuidad intertextual entre cine y televisión en concreto, que son los medios que fungen de "naves nodriza" en los estudios sobre narraciones transmediáticas, nada mejor que recurrir a las documentadas y amenas obras de Concepción Cascajosa $(2004,2006)$.
} 
ñas pero implicadas para que sean capaces de ahondar en la historia, porque esta les atrapa y a la vez está preparada para responder a esa tensión vertical. Mittell habla de un "forensic fandom" que estimula a los espectadores a profundizar. En cualquier caso, ambos movimientos pueden ser y de hecho funcionan complementariamente, y en palabras de Mittell no suponen una jerarquía, sino más bien formas distintas de compromiso con la historia (Mittell, 2009).

Un segundo reparo al término es el que supone que las NT no son más que un fenómeno mercantil relacionado, sí, con la ficción, pero característico de la explotación de una franquicia por los conglomerados multimedia que gestionan sus derechos y aprovechan las sinergias multimediales de su negocio (Dena, 2004). Vinculado a esto, también se suele enfriar el entusiasmo con que muchos investigadores recibieron la llamada por Jenkins "cultura participativa", el contenido generado por el usuario, pues esa productividad amateur es rentabilizada por las corporaciones multimedia: bien porque la creatividad no lucrativa provee de datos inestimables sobre esos usuarios en tanto consumidores, bien porque, si la fanfiction nació con una impronta en cierto modo de "fanzine" en la era digital, ha sido rápidamente cooptada por las franquicias, que encauzan y mercantilizan de alguna manera ese tráfico, al recompensar al usuario activo con acceso a más material exclusivo, e incluso al convertir la productividad no registrada en producto corporativo y sujeto a derechos (Andrejevic, 2008; Bratich, 2011).

Jenkins nunca afirmó que la narrativa fuera la única dimensión de la transmedialidad, ni mucho menos, sino que reconoció otras en cierto modo ajenas pero interrelacionadas con la narración como entretenimiento (Jenkins, 2009a; 2009b). Precisamente el requerimiento de que las narraciones de cada uno de los distintos medios proporcionen experiencias completas y autónomas, aunque estén coordinadas a un nivel superior por un macrodiseño (overdesign) narrativo, es una exigencia a medias industrial-comercial y propiamente narrativa: se pretende que el espectador, lector o jugador pueda extraer experiencias satisfactorias de su visionado, lectura o partida singular - pues remitirle inapelablemente a otro medio para completar el arco narrativo supondría frustrar sus expectativas, seguramente-, pero a la vez sugerir que otras experiencias más profundas y quizá enriquecedoras sobre el universo narrativo le están esperando en otras plataformas. No se trata, por tanto, de descoyuntar una narración, trocearla y repartirla en medios distintos para venderla por piezas más ventajosamente que de una sola vez: eso es una caricatura del procedimiento. Se trata de que el universo narrativo, preferentemente amplio, complejo, dispone los relatos interrelacionados que lo forman en sustancias expresivas, en medios y plataformas distintos, que la transmedialidad está al servicio de la narración, de una narración que seguramente tiene en mente un receptor transmedia (o lo construye, que tanto da): ¿translector in fabula?

Y la tercera objeción supone que las NT, caso de existir tal y como las describe Jenkins, no serían un gran progreso en términos narrativos, sino más bien una regresión un tanto ingenua: ninguna narración está absolutamente completa, porque el cuento nunca se cuenta del todo. La pretensión transmediática de contarlo todo es contraria a la naturaleza esencialmente reservada o reticente de cualquier narración que se precie (Bordwell, 2009). Por otro lado, y como advertía Eco (1992: 219), los 
mundos posibles narrativos son siempre pequeños mundos, y el texto debe invitar a los lectores a una tarea "cosmológica" relativamente fácil. Frente a esta objeción, Jenkins arguye que los vacíos que deja todo relato son imposibles de llenar, incluso (sobre todo, diríamos) en un universo transmedial, por definición complejo y poliédrico: sus posibilidades son inagotables, porque cada pieza de información nueva que se aporta es la ocasión de nuevos interrogantes, de especulaciones y anticipaciones de la prosecución de la trama en varias direcciones (Jenkins, 2009b). Matt Hills ya había acuñado, como uno de los requisitos de los textos de culto, el término hiperdiégesis, definido como un vasto y detallado espacio narrativo del cual solo vemos una fracción en el texto. Ahora bien, dicha fracción opera de acuerdo a principios de una lógica interna tan sistemática, que parece sostener toda una arquitectura o una geometría tridimensional, no visible pero consistente (Hills, 2002: 137). Y consideraba que cuanto más intricado el universo narrativo, mayor el sentimiento de coherencia y de continuidad y la confianza del espectador, así como mayor el desafío y la recompensa que encuentra el fan no sólo al recorrerlo, sino al investigarlo, al jugar al juego que propone. De ahí el predominio de la ciencia ficción, el terror y la fantasía en los textos de culto (138).

\section{RETOS DE LAS NT}

Como suele suceder, algunas objeciones, debidamente proporcionadas, se nos transforman en desafíos extraordinariamente estimulantes con respecto a las NT, y abogan a nuestro juicio por su interés académico. En primer lugar, las NT en cierto modo deberían obligarnos a borrar las fronteras y a abordar conjuntamente aquellas dos provincias de los estudios narratológicos que frecuentemente se han concebido como difícilmente conciliables: la que separa una narratología modal, que atiende a las formas de expresión según el soporte en que se narra (imágenes, palabras habladas, texto escrito, etc.) y una narratología temática, la que atiende a la historia narrada misma, las acciones y funciones de los personajes, con independencia del medio de expresión empleado (Genette, 1998: 14-15; Gaudreault y Jost, 1995: 19-20). Y es que las NT obligan a pensar simultáneamente la narración en términos de una y de la otra, pero no a efectos de comparación (que ha deparado todo un subgénero a caballo de los estudios literarios y filmicos, sobre todo, relativo a las adaptaciones), sino a efectos de construcción narrativa coordinada en medios distintos: convergencia narrativa en divergencia textual y medial (D. Johnson, 2009; Smith, 2009: 12).

Por otro lado, las NT reavivan la discusión sobre los modelos de mundo, sobre el pacto ficcional y sobre la capacidad de construir universos narrativos complejos a través de la dispersión transmedial: se ha sugerido que las narraciones del nuevo milenio no se contentan con la voluntaria suspensión de la incredulidad, sino promueven una activa y decidida construcción de la credulidad (Murray, 1997). Esa construcción pasa por el diseño de un universo amueblado con una geografía detallada, con personajes y sus respectivas psicologías, con estirpes y sus genealogías, incluso, en los casos más elaborados y fantásticos, con sus dioses y sus cosmogonías, con una historia dotada de hitos decisivos, cronologías: en definitiva, un univer- 
so que no deja de estar ahí, de evolucionar, de transformarse, aun cuando dejemos de mirarlo (como el nuestro propio). Y hay un impulso "enciclopédico", característico de las ficciones interactivas contemporáneas, que nos mueve a explorar y pretender dominar -algo muy difícil de lograr- el entero universo narrativo. Esa pulsión la promueve desde luego el autor, pero la comparte entusiásticamente el espectador: deseamos experimentar una inmersión en la historia, y tendemos a reforzar, más que a cuestionar, el realismo de nuestra experiencia. Y esa avidez no puede ser entendida cabalmente sin ponerla en relación con la red: allí donde los textos están en promiscua vecindad con todos sus intertextos, al alcance de un clic, allí donde los lectores o espectadores se vuelven compiladores, críticos y autores ("prosumidores" o "produsuarios"), tan solo con el estímulo preciso, la placentera dedicación y una moderada pericia técnica, allí donde, en fin, esos lectores o espectadores no están si se sienten solos, sino arropados por una comunidad que late en una longitud de onda armónica y que afianza y refuerza cotidianamente la consistencia del universo narrativo de su elección.

Además, y de manera solo aparentemente contradictoria con lo anterior, las NT plantean un nuevo reto, como el lema de este número monográfico sugiere: si la narración no es un fenómeno sólo ficcional (no todas las narraciones son ficticias, como no todas las ficciones son narrativas), sino que es la arquitectura básica de cualquier relato, entonces las NT están también por derecho al otro lado de esa frontera que separa el territorio de la ficción del de la no-ficción. Es decir, como el propio Jenkins sugirió en el texto más influyente sobre NT, la transmedialidad narrativa es sin duda patrimonio también de los realities televisivos, por ejemplo (Survivor era el caso que él ponía), y tendencialmente de cualquier texto sometido a un centrifugado a lo largo y ancho del universo mediático, siempre que sea su narración la sometida a dispersión transmedial (la noticia, por ejemplo, como señala Cristina Peñamarín en este mismo volumen, pero también los documentales, las crónicas, el pensamiento político, el activismo social a través de la red: Mittell, 2010: 213-258; Jenkins, 2012, Scolari y otros, 2012). De hecho, el "giro transmediático" que proponíamos en el título de este trabajo se aviene muy bien con el "giro narrativo" que ya ha sido descrito en las ciencias sociales (Bruner, 1991; Kreiswirth, 1992, 2000), del que sería brazo secular tecnológico (articulado y tentacular, además). No es que ambos se presupongan, pero sin duda hay una armonía preestablecida entre la narrativización de multitud de discursos y la multitud de medios y plataformas en que pueden encarnarse, desplegándose en ellos.

En cierto modo, y este es el cuarto reto que planteamos, no es la ficcionalidad estrictamente, sino la serialidad, la que se revela como la condición más necesaria aunque no suficiente- para hablar de NT. La serialidad "monomediática", digamos, desde los folletines decimonónicos a las series de televisión, ya fue la manera en que planteamiento, nudo y desenlace de una trama podían aparecer disjuntos, en que el contrato de un relato, la adquisición de una competencia, la performance y la sanción se encarnaban en textos distintos, en que programas narrativos primarios y secundarios o cambios en el sujeto de la enunciación se manifestaban en sucesivas entregas. Como Jenkins ha señalado, las NT pueden ser concebidas como versiones hiperbólicas de las narraciones seriales, con la particularidad de que las entregas de 
información relevante no solo se dosifican en cápsulas que son los capítulos o episodios dentro de un mismo medio de expresión, sino también, coordinadamente, a través de varios medios de expresión (Jenkins, 2009a). En otras palabras, las NT son hiperseriales (Murray, 1997).

Esa hiperserialidad tiene una dimensión creativa, narrativa propiamente dicha y otra económica, obviamente, pero también una tecnológica: parte sin duda de la televisión como nave nodriza acreditada en narraciones serializadas, del texto televisivo clásico, emitido con la periodicidad que le es propia en la parrilla, pero alcanza una dimensión nueva cuando otros dispositivos permiten el acceso a la carta a ese mismo texto (DVD, video-on-demand, video en streaming), o cuando el acceso es posible a través de otras pantallas o dispositivos (ordenadores portátiles, teléfonos móviles, tabletas). Y si esos dispositivos no se limitan a entregar el mismo contenido televisivo, ni a volver a envasarlo con algunos extras que sirvan de gancho, sino que plantean una expansión y profundización narrativas y alientan la participación del fan, entonces estamos en plena transmedialidad de los relatos asociados a ese universo (Askwith, 2007) ${ }^{5}$.

$\mathrm{Y}$ en quinto lugar, las NT suponen otro desafío adicional a los tradicionales macrocompartimentos en que parcelamos los productos de las industrias culturales. Mientras parecía obvia hace unos años la diferencia entre, por un lado, los productos culturales propiamente dichos, que generan valor económico en sí mismos pues sometidos a derechos de propiedad intelectual y comercializados en paquetes creativos (libros, filmes, discos, videojuegos, cómics, series de televisión) y por otro los paratextos promocionales (Gray, 2010) destinados a publicitar dichos productos, y que se entregan gratuitamente a las audiencias, a menudo a través de los mismos medios de difusión que aquellos (los promos, trailers, teasers, clips en primer lugar, y luego los formatos de la red: páginas web, blogs, webisodes, mobisodes), las NT parecen haber diluido, more narrativa, esa diferencia: no sólo cada producto propiamente dicho es una promoción cruzada para todos los demás, sino que los paratextos publicitarios parecen convertirse en un satélite más de la constelación narrativa transmedial, contribuir en pie de igualdad con los textos propiamente dichos a la construcción del relato, como hemos visto ejemplarmente en el caso de True Blood ${ }^{6}$. De hecho, podría sostenerse que esa doble dimensión promocional de las NT que acabamos de describir no es más que la devolución de un antiguo préstamo. Al fin y al cabo, la publicidad fue el primer mensaje masivo decididamente transmedial de la historia: el mensaje publicitario, que nunca tuvo un soporte exclusivo y sí la vocación de colonizarlos a todos, siempre debió acomodar una única idea creativa, con frecuencia narrativa o narrativa in nuce, a una variedad de medios y soportes

\footnotetext{
${ }^{5}$ Para una discusión muy interesante sobre la serialidad clásica de los medios masivos como pretendidamente "femenina" y sobre los connotaciones "masculinas" atribuidas a la era de la convergencia y al fan más implicado y colaborativo, cfr. D. Johnson (2011).

${ }^{6}$ En buena medida, la famosa huelga de los guionistas de Hollywood de 2007-08 se debió a que las cadenas de televisión consideraban que los contenidos web -como webisodios y blogs ficcionales, es decir, extensiones transmediales de la trama- eran contenido promocional, y por lo tanto no los pagaban a los guionistas. La huelga obligó a que las industrias del cine y la TV consideraran trabajo creativo, y por lo tanto objeto de retribución económica, dichas producciones.
} 
distintos, procurando que se recordaran y complementaran unos a otros sin provocar hastío. Transmedialidad publicitaria y ficción narrativa encuentran un territorio común: la publicidad de la marca y de sus productos (la nave nodriza y todas sus extensiones transmediales en cualquier medio y plataforma) se vuelve funcional a la diégesis ficcional, no discurso extradiegético, para- o metaficcional.

$\mathrm{Si}$ arriba sugeríamos que los procesos tecnológicos y económicos de la transmedialidad habían sido insuflados de espíritu gracias a la narratividad, ahora añadimos que las narraciones transmediáticas necesitan complementarse probablemente con ese tercer ingrediente promocional, que se introduce entre ambos, y que en esa tesitura -textura y textualidad- experimenta una verdadera transfiguración.

\section{REFERENCIAS BIBLIOGRÁFICAS}

ANDREJEVIC, M. (2008). «Watching television without pity: the productivity of online fans». Television and New Media, vol. 9, 24-46.

BARTHES, R. (1993). «Introducción al análisis estructural de los relatos» [1966], en La aventura semiológica. Barcelona: Paidós.

Bernardo, N. (2011). The Producer's Guide to Transmedia: How to Develop, Fund, Produce and Distribute Compelling Stories Across Multiple Platforms, Beactive.

Bordwell, D. (2010). «Now Leaving from Platform 1», on Observations on Film Art, http://www.davidbordwell.net/blog/2009/08/19/now-leaving-from-platform-1/ Consultado el 6 de diciembre de 2012.

Bratich, J. (2011). «User Generated Discontent: Convergence, Polemology and Dissent». Cultural Studies 25 (4-5): 621-40.

BRUNer, J. (1991). «The Narrative Construction of Reality», Critical Inquiry 18-1 ,1-21.

Cascajosa, C. (2004). El espejo deformado: procesos de hipertextualidad en la ficción audiovisual norteamericana. Sevilla: Universidad de Sevilla.

(2006). De la TV a Hollywood: un repaso a las películas basadas en series. Madrid: Arkadin.

DAVIDSON, D. et al. (2010). Cross-media communications: and introduction to the art of creating integrated media experiencies. ETC Press. Recuperado el 3 de septiembre de 2011, de

Dena, C. (2004). «Current State of Cross Media Storytelling: Preliminary observations for future design», Delivered by Monique de Haas at 'Crossmedia communication in the dynamic knowledge society' networking session, European Information Systems Technologies Event, The Hague, Netherlands, 15 Nov, 2004.

(2008). «Emerging participatory culture practice: Player-Created tiers in Alternate Reality Games». Convergence: The International Journal of Research into New Media Technologies 14, 41-57.

(2009). «Transmedia Practice: Theorising the Practice of Expressing a Fictional World across Distinct Media and Environments». PhD Dissertation. University of Sydney.

ECO, U. (1992). Los límites de la interpretación. Barcelona: Lumen.

Evans, E. (2008). «Character, Audience Agency and Transmedia Drama». Media Culture \& Society. 30 (2), 197-213.

(2011). Transmedia Television. Audiences, New Media and Daily Life. New York: Routledge. 
Gaudreault, A. y Jost, F. (1995). El relato cinematográfico: cine y narratología. Barcelona: Paidós.

Genette, G. (1987). Seuils. París: Seuil.

(1989). Palimpsestos: la literatura en segundo grado. Madrid: Taurus [1982].

(1998). Nuevo discurso del relato. Madrid. Cátedra [1993].

Giovagnoli, M. (2011). Transmedia storytelling. Imagery, Shapes and Techniques. Pittsburgh: ETC Press.

Gomez, J. (2007). «8 defining characteristics of a trans-media production»

http://pganmc.blogspot.com.es/2007/10/pga-member-jeff-gomez-left-assembled.html

Gray, J. (2010). Show Sold Separately: Promos, spoilers and other media paratexts. New York: New York U.P.

Hardy, J. (2010). Cross-Media Promotion. New York: Peter Lang.

HiLls, M. (2002). Fan Cultures. New York: Routledge.

JENKINS, H. (2003). «Transmedia Storytelling: Moving characters from books to films to video games can make them stronger and more compelling». Technology Review. [Fecha de consulta: 15/01/12].

http://www.technologyreview.com/Biotech/13052/?a $=\mathrm{f}$

(2006). Convergence Culture. Where New and Old Media Collide. Nueva York : New York U.P.

(2007). «Transmedia Storytelling 101», en Confessions of an Aca-Fan.

http://henryjenkins.org/2007/03/transmedia_storytelling_101.html

(2009a). «The Revenge of the Origami Unicorn: Seven Principles of the Transmedia Storytelling».

http://henryjenkins.org/2009/12/the_revenge_of_the_origami_uni.html http://henryjenkins.org/2009/12/revenge_of_the_origami_unicorn.html

(2009b). «The Aesthetics of Transmedia: In response to David Bordwell».

$\overline{\mathrm{http}}: / /$ henryjenkins.org/2009/09/the_aesthetics_of_transmedia_i.html

http://henryjenkins.org/2009/09/the_aesthetics_of_transmedia_i_1.html

http://henryjenkins.org/2009/09/the aesthetics of transmedia ${ }^{-} 2 . h t m l$

(2010). «Transmedia Storytelling and Entertainment: An annotated syllabus.» Continuum 24(6), 943-958.

(2011a). «Transmedia Storytelling 202: Further Reflections».

http://henryjenkins.org/2011/08/defining_transmedia_further_re.html

(2011b). «Seven Myths about Transmedia Storytelling debunked».

$\overline{\mathrm{http}}$ ://www.fastcompany.com/1745746/seven-myths-about-transmedia-storytelling-debun-

ked

(2012). «Contextualizing \#Kony2012: Invisible Children, Spreadable Media,

Transmedia Activism».

http://henryjenkins.org/2012/03/contextualizing_kony2012_invis.html

JoHnson, C. (2007). «Telebranding in TVIII: The network as brand and the programme as

brand», New Review of Film and Television Studies, 5(1), 5-24.

http://web.mit.edu/uricchio/Public/television/Catherine\%20Johnson\%20telebranding.pdf

JoHnson, D. (2009). «The Fictional Institutions of Lost: World Building, Reality, and the

Economic Possibilities of Narrative Divergence». En Reading Lost. Perspectives on a

Hit Television Show. Ed. Roberta Pearson. London: IB Tauris, 29-52.

(2011). «Devaluing and revaluing seriality: The gendered discourses of media fran-

chising». Media, Culture \& Society 33 (7), 1077-1093.

http://mcs.sagepub.com/content/33/7/1077.full.pdf + html 
Kinder, M. (1991). Playing with Power in Movies, Television and Video Games: From Muppet Babies to Teenage Mutant Ninja Turtles. Berkeley: University of California Press.

KreIswirTh, M. (1992). «Trusting the Tale: The Narrativist Turn in the Human Sciences». New Literary History 23, 629-657.

(2000). «Merely Telling Stories? Narrative and Knowledge in the Human Sciences». Poetics Today 21, 293-318.

Kress, G. y Van Leeuwen, T. (2001). Multimodal Discourse: The Modes and Media of Contemporary Communication. Londres: Arnold.

LacAlle, R. (2011). «Televisión y Web 2.0», Ámbitos, 20, 87-107.

Long, G. (2007). Transmedia Storytelling: Business, Aesthetics and Production in the Jim Henson Company. Cambridge: MIT Master's Thesis.

LóPEZ-VARElA, A. (2011). "Intertextuality and Intermediality as Cross-cultural Comunication Tools: A Critical Inquiry». Cultura. International Journal of Philosophy of Culture and Axiology 8(2)/2011: 7-22.

Maguregui, C., A. Piscitelli y C. A. Scolari (comps.). (2010). Lostología. Buenos Aires: Cinema.

Mittell, J.(2006). «Narrative complexity in contemporary American Television». Velvet Light Trap 58 (1): 29-40.

http://juliaeckel.de/seminare/docs/mittell\%20narrative\%20complexity.pdf (2009). «To Spread or to Drill?»

$\overline{\mathrm{http}}$ ://justtv.wordpress.com/2009/02/25/to-spread-or-to-drill/ (2010). Television and American Culture. Nueva York y Oxford: Oxford U.P.

Murray, J. H. (1997). Hamlet on the Holodeck: The Future of Narrative in Cyberspace. New York: The Free Press.

Page, R. (ed) (2009). New perspectives on narrative and multimodality. Londres: Routledge. Pearson, R. (ed.) (2009). Reading Lost: Perspectives on a Hit Television Show. London: I.B. Tauris.

Perryman, N. (2008). «Doctor Who and the convergence of media: a case study in 'transmedia storytelling». Convergence 14: 21-39. [Fecha de consulta: 12/01/12].

PHILliPs, A. (2012). A creator's guide to transmedia storytelling: how to captivate and engage audiences across multiple platforms Nueva York: McGraw Hill.

RODRÍGUEZ FERRÁNDIZ, R. (2001). Apocalypse Show: intelectuales, televisión y fin de milenio. Madrid: Biblioteca Nueva.

(2012). «Sangre fresca publicitaria: publicitaria: True Blood y las transfusiones de la ficción». Anàlisi. Monogràfic Audiovisual 2.0, 65-80.

http://www.analisi.cat/ojs/index.php/analisi/article/view/m2012-rodriguez/m2012-rodriguez

SCOLARI, C. A. (2009). «Transmedia Storytelling: Implicit Consumers, Narrative Worlds, and Branding in Contemporary Media Production». International Journal of Communication 3, 586-606. [Fecha de consulta: 15/01/12].

http://ijoc.org/ojs/index.php/ijoc/article/view/477/336. (2013). Narrativas Transmedia: cuando todos los medios cuentan. Barcelona: Deusto.

SCOLARI, C.A. et alii (2012). «Narrativas transmediáticas, convergencia audiovisual y nuevas estrategias de comunicación». Quaderns del CAC, 38, vol. XV (1), 79-89.

http://www.cac.cat/pfw_files/cma/recerca/quaderns_cac/Q38_scolari_et_al_ES.pdf

Transmedia Manifest: The Future of Storytelling (2012). http://www.transmediamanifest.com/ 


\begin{abstract}
RESUMEN
La reflexión en torno a las narraciones transmediáticas ha sido muy intensa en los últimos diez años. En este artículo intentamos desbrozar el concepto, dar cuenta de su especificidad y mostrar algunos ejemplos clásicos y otros más recientes. También apuntaremos algunas dificultades y retos que plantea a los estudios no sólo narratológicos, sino también en los márgenes entre estos y otros dominios tanto semióticos como de los Media Studies: las dimensiones y los límites de una "historia" de la narración transmedia, las explicaciones económicas de su pujanza actual, el afán de construcción de universos narrativos complejos y la inmersión en ellos de los fans, el papel crucial de la serialidad, la dimensión promocional y más en general paratextual de las narraciones trasmediáticas y finalmente la extensión del fenómeno más allá del dominio de la ficción. El "giro narrativo" descrito en las ciencias sociales y en muchos discursos públicos hace ya unas décadas debería complementarse ahora con un "giro transmediático", funcional al primero y a la manera de su brazo secular (tecnológico y económico).
\end{abstract}

Palabras clave: Narraciones Transmediáticas, Universos Transmedia, Henry Jenkins, CrossPromotion, Paratextualidad, Serialidad.

\title{
Stories by all available means: a transmedia turn?
}

\begin{abstract}
Studies on Transmedia Storytelling have been a very active area of research in the last ten years. This paper tries to clear up the matter by providing an overwiew of the evolution of the concept, to account for its specificity and to show some examples. In conclusion I will point the difficulties and challenges posed in narratological studies, but also in the margins between these and other domains of both Semiotic and Media Studies: A history of transmedia storytelling, the economic explanations of its current strength, the desire to build complex narrative universes and the commitment of fans, the crucial role of seriality, the promotional and paratextual dimension of many transmedia narratives, and finally the extent of the phenomenon, crossing over into fiction and non-fiction territories. The "narrative turn" in Social Sciences and many social discourses, in vogue since a few decades ago, should be complemented with a "transmedia turn".
\end{abstract}

Keywords: Transmedia Storytelling, Transmedia Universes, Henry Jenkins, Cross-promotion, Paratexts, Seriality. 